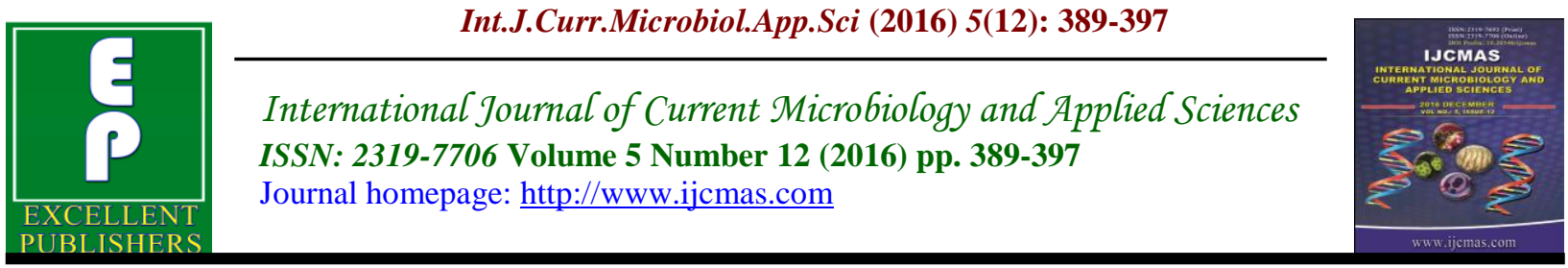

Original Research Article

http://dx.doi.org/10.20546/ijcmas.2016.512.043

\title{
Bioethanol Production from Cotton Stalk Hydrolysate using Immobilized Co culture of Saccharomyces cerevisiae and Pachysolen tannophilus
}

\author{
Mirza Zaheer Baig* and Smita M. Dharmadhikari
}
Department of Microbiology, Government Institute of Science, Aurangabad, India
*Corresponding author

\section{A B S T R A C T}

Keywords

Fermentation,

Bioethanol, Cotton

stalk, Saccharomyces

cerevisiae,

Pachysolen

tannophilus,

Immobilization.

Article Info

Accepted:

18 November 2016

Available Online:

10 December 2016
The present study focuses on bioethanol production from cotton stalk hydrolysate using immobilized cell fermentation. For this, cotton stalk was hydrolyzed by two stage acid treatment, and the obtained hydrolysate was detoxified and fermented using immobilized co culture of SaccharomycescerevisiaeMTCC36 and Pachysolentannophilus MTCC1077.The results showed that, maximum ethanol concentration of $3.94 \mathrm{~g} / \mathrm{L}$ was achieved after 36 hours of fermentation by consuming $90.18 \%$ of total available sugar, with a corresponding yield of $0.142 \mathrm{~g} / \mathrm{g}$ biomass, $0.221 \mathrm{~g} / \mathrm{g}$ of holocelluloses, $0.355 \mathrm{~g} / \mathrm{g}$ of fermentable sugar, and fermentation efficiency of $69.53 \%$ respectively. As recycling of immobilized cell is concern, the first two batches gave significantly similar results in concentration, yield and fermentation efficiency, while during third cycle of fermentation, beads became disintegrated.

\section{Introduction}

Increasing energy demand and decreasing fossil reservoirs, diverts the concentration of research towards an alternative energy sources. These energy sources must be expected to satisfy several requirements, including substantial reduction in greenhouse gasses emission, world wide availability of feedstock and capability of being produce from renewable resources. Many alternative fuel sources have been explored and among them fuel ethanol have received most attention. Ethanol is renewable energy source produced through fermentation of sugar. As a substrate, conventional crop such as corn and sugarcane are unable to meet the global demand of bioethanol production due to their primary value of food and feed therefore, lignocellulosic substance such as agricultural wastes are emerged as attractive feedstock for bioethanol production (Dien $e t$ $a l ., 1999)$. In present study cotton stalk was used as feedstock due to its lignocellulosic nature and potential availability.

Before going to ethanol fermentation, the feedstock needs to be process by scarification technology in order to retain fermentable sugars. Acid hydrolysis is a simple and easy method to perform and is prominently used for depolymerization of biomass into fermentable sugar. Acid 
hydrolysis was carried out in two stages including concentrated acid decrystallization followed by dilute acid hydrolysis with steam and heat treatment (Liao et al., 2006).As soon as the monomers are produced, further decompositions occur, yielding other unexpected compounds such as furans and phenolics; which negatively impact on fermentation process. To overcome these inhibitors, detoxification of acid hydrolysate was the next key step in series before fermentation (Chandel et al., 2007).

The use of immobilized cell offers number of advantages such as enhancement of fermentation productivity, feasibility of continuous processing, cell stability, lower costs of recovery and recycling in downstream processing (Kourkoutas et al., 2004).Cell entrapment using calcium alginate gel is a well-established technique which has been extensively studied because of its simplicity and non-toxicity. Alginic acid is natural polymer found in marine algae (Davis et al., 2003). The fact that free carboxylic groups are repeated in the macromolecule makes them accessible to divalent cations such as $\mathrm{Ca}^{2+}$, and formation of coordination complexes occurs ingelation process (Vullo and Wachsman, 2005). The preparation process is known as electrostatics droplet generation method, which is carried out by drop-wise addition of cell suspended in sodium alginate in to the calcium chloride solution, where beads are immediately formed in the calcium alginate gel (Goksungur and Zorlu, 2001).

Immobilization of cells for fermentation has developed to eliminate inhibition caused by high concentration of substrate and products, also to enhance the productivity and yield of ethanol production (Baptista et al., 2006). In present study, co culture of Saccharomyces cerevisiae and Pachysolen tannophilus were immobilized in calcium alginate beads and evaluate its potential for ethanol production using cotton stalk hydrolysate as sole carbon source.

\section{Materials and Methods}

\section{Feed stock preparation}

Cotton stalks of spp. Gossypium hirsutum NHH44 was collected, dried, debarked, and ground to $1 \mathrm{~mm}$ particle size and stored at room temperature. Compositional analysis showed that, it contains approximately $42.40 \%$ glucan and $23.20 \%$ xylan (The individual monomer carbohydrate content was determined by the method of LAP \# 002 of NREL using HPLC, Zodiac. Ltd). Klason (acid insoluble) lignin was found to be $24.18 \%$, determined by method adopted by Teramoto et al., (2008).

\section{Microorganisms}

Saccharomyces cerevisiae MTCC 36 and Pachysolen tannophilus MTCC 1077 were procured from Microbial Type Culture Collection, IMTECH-Chandigarh, India and were maintained on Yeast and Malt Extract Agar (YMmedium). The medium was prepared in distilled water by adding $0.3 \%$ yeast extract, $0.3 \%$ malt extract, $0.5 \%$ peptone and $1 \%$ glucose, and $\mathrm{pH} 6.5$.

\section{Saccharification and detoxification of cotton stalk}

Cotton stalk was subjected to dual stage sulfuric acid treatment. During its first stage $75 \% \mathrm{H}_{2} \mathrm{SO}_{4}$ was used to decrystallize the biomass under specific sample acid ratio of 1:2 (by weight) followed by diluting the same up to $1 \mathrm{~N}$ in second stage, then employing steam under pressure at $121^{\circ} \mathrm{C}$ in an autoclave for 30 minutes and four hour heat treatment at $90^{\circ} \mathrm{C}$ in water bath (Baig, 
2014). The obtained acid hydrolysate was detoxified by addition of dried lime up to $\mathrm{pH}$ 10 for an hour and then filtered and $\mathrm{pH}$ was readjusted up to 6 with acid. This is followed by $4 \%(\mathrm{w} / \mathrm{v})$ charcoal treatment for half an hour with stirring and then filtered (Baig and Dharmadhikari, 2014). The obtained filtrate solution was used as sole carbon source for fermentation studies.

\section{Inoculum development}

Cell mass of Saccharomyces cerevisiae and Pachysolen tannophilus required for the growth of inoculum was prepared by transferring it aseptically from slants to YM medium. The cells were allowed to grow aerobically in flask at $30^{\circ} \mathrm{C}$ on rotary shaker incubator with $150 \mathrm{rpm}$ for 48 hours. After incubation, completely activated yeast cell were harvest by centrifugation with 4000 $\mathrm{rpm}$ at $4^{\circ} \mathrm{C}$ for 10 minutes, washed with distilled water and transferred to cotton stalk hydrolysate supplemented with $0.5 \%$ yeast extract, $1 \%$ peptone and $\mathrm{pH}$ was adjusted to 5.5. The flasks were incubated on rotary shaker incubator with $150 \mathrm{rpm}$ at $30^{\circ} \mathrm{C}$ for 24 hours and grown aerobically to promote healthy growth of yeast cell in hydrolysate. After incubation these activated cells of Saccharomyces cerevisiae and Pachysolen tannophilus were mixed in the proportion of $60 \%$ and $40 \%$ respectively. Cells were quantified to ensure the initial inoculation stayed at approximately $6 \times 10^{7} \mathrm{cfu} / \mathrm{mL}$ corresponding to 10 gram dry weight/liter. Total suspension of yeast cell was centrifuged at $5000 \mathrm{rpm}$ for 5 minute at $4{ }^{\circ} \mathrm{C}$ and cell pellets were washed with distilled water and stored at $4^{\circ} \mathrm{C}$ for beads preparation.

\section{Preparation of beads from co culture inoculum of yeast cells}

To carry out immobilization, $2 \% \mathrm{CaCl}_{2}$ solution was prepared in an aqueous medium and kept at $4^{\circ} \mathrm{C}$ for chilling. Subsequently sodium alginate solution (2\% $\mathrm{w} / \mathrm{v}$ ) was prepared in hot water by stirring on magnetic stirrer. Dry pellets (inoculum) of yeast cell which was stored for bead preparation, mixed with sodium alginate solution thoroughly to form homogenous mixture. This homogeneous mixture was extruded slowly drop by drop through stainless steel needle using syringe pump into $2 \%$ chilled $\mathrm{CaCl}_{2}$ solution which form the calcium alginate beads of yeast cell containing co-culture of Saccharomyces cerevisiae and Pachysolen tannophilus. These beads were aseptically stored at $4^{\circ} \mathrm{C}$ for further studies.

\section{Ethanol production using immobilized yeast cells}

Fermentation was performed in $250 \mathrm{ml}$ of Erlenmeyer flask containing $150 \mathrm{ml}$ of cotton stalk hydrolysate to fulfill the requirement of semi aerobic mode of aeration. All the fermentations were operated in batch manner with a fixed parameter and supplemented with $0.5 \%$ yeast extract, $1 \%$ peptone, $\mathrm{pH} 5.5$ and temperature of $30^{\circ} \mathrm{C}$. The fermentation was initiated with inoculation of calcium alginate beads of Saccharomyces cerevisiae and Pachysolen tannophilus(corresponds to $10 \%$ co culture inoculum) into flasks and sealed with aluminum foil and allowed to ferment on rotary shaker incubator with an agitation rate of $120 \mathrm{rpm}$. Samples were collected at 12 hours interval throughout the fermentation from individual flask at one time, so as to maintain the ideal environmental condition during fermentation (72 hours), and were subjected to estimation of ethanol and residual sugar simultaneously (Baig, 2014).

\section{Recycling of immobilized yeast cells}

In order to examine the recycling potential of immobilized cells, at the end of 
fermentation cycle, the calcium alginate beads were retained, washed with sterile saline and transferred to the similar volume of fresh medium for the next cycle of fermentation. The cycles were repeated again and again till change in physiology of beads or productivity of fermentation was observed.

\section{Analytical methods}

The DNSA method of Miller, (1959) was adopted to quantify the amount of reducing sugars present in the sample. Glucose oxidase method, for an enzymatic assay of glucose was performed by following the guideline given by Bregmeyer et al., (1974). Total content of phenolic compound in hydrolysate was determined by FolinCiocalteus (FC) method (Singleton and Rossi, 1965).Furans were estimated with spectophotometric method as described by Martinez et al., (2000).Ethanol estimation was carried out by Gas Chromatography (Shimadzu Japan). GC was carried out according to NREL procedure LAP \# 011, using ZB-Wax column $(30 \mathrm{~mm} \times 0.25 \mathrm{~mm})$ with Flame Ionization Detector (FID). Cell density was measured turbidometrically at $600 \mathrm{~nm}$ by using UV-VIS spectrophotometer (Srilekha Yadav et al., 2011).

\section{Fermentation efficiency}

Fermentation efficiency was calculated as

Fermentation efficiency $=\frac{\text { Practical yield of ethanol }}{\text { Theoretical yield of ethanol }} \times 100$

Theoretical yield is 0.511 gram per gram of sugar consumed.

\section{Results and Discussion}

\section{Saccharification and detoxification of cotton stalk}

The two stage acid hydrolysis of cotton stalk yielded maximum fermentable sugar and specifically D-glucose of $0.49 \mathrm{~g} / \mathrm{g}$ and 0.36 $\mathrm{g} / \mathrm{g}$ of biomass (native cotton stalk) respectively. The byproducts of hydrolysis such as furans and phenolics were also formed with a concentration of $1.971 \mathrm{mg} / \mathrm{L}$ and $4.909 \mathrm{~g} / \mathrm{L}$ respectively (Table.1). To overcome these inhibitors, detoxification with over liming up to $\mathrm{pH} 10$ for an hour followed by filtration and by maintaining $\mathrm{pH}$ $6 ; 4 \%$ charcoal treatment for half an hour gives maximum reduction in inhibitors including $92.69 \%$ furans and $88.89 \%$ phenolics while $19.84 \%$ sugar losses were also reported during process (Baig and Dharmadhikari, 2014). The detoxified hydrolysate achieved having sugar concentration of $11 \mathrm{~g} / \mathrm{L}$, corresponds to a yield of $0.396 \mathrm{~g} / \mathrm{g}$ of biomass; it is then exposed to fermentation for ethanol production.

\section{Fermentation using immobilized co} culture

Fermentation was initiated by introducing Ca-alginate beads containing co culture inoculum of Saccharomyces cerevisiae and Pachysolen tannophilus (which corresponds to $10 \%$ inoculum), into flask contains cotton stalk hydrolysate and was incubated at $30^{\circ} \mathrm{C}$ for 72 hours. The outcomes of all 
experiments were analyzed in terms of substrate utilization and product formation and reliability of the results were checked by passing through ANOVA. As the fermentation process started, the data showed that ethanol was not detected in first 6 hours of fermentation, while it commence from 12 hours onwards and reached maximum at 36 hours of fermentation. The concentration of ethanol was stared from $0.71 \mathrm{~g} / \mathrm{L}$ after 12 hours of fermentation and reached to $3.94 \mathrm{~g} / \mathrm{L}$ at 36 hours of fermentation corresponds to an yield of $0.142 \mathrm{~g} / \mathrm{g}$ of biomass (native cotton stalk), $0.221 \mathrm{~g} / \mathrm{g}$ of holocelluloses and $0.355 \mathrm{~g} / \mathrm{g}$ of fermentable sugar available for yeast cell and during this stage the highest fermentation efficiency was recorded as $69.53 \%$. Meanwhile, the sugar concentration in the medium dropped sharply to more than $90 \%$ within 36 hours of fermentation and stayed constant thereafter. These findings were harmony with the results reported earlier (Wendhausen et al., 2001).

\section{Effect of recycling on ethanol production by immobilized yeast cells}

Cycles of repeated batch operations with the immobilized yeast performed, using the same process conditions as in the first batch fermentation, each of them tested for 36 hours. The ethanol concentration was noted as $3.94 \mathrm{~g} / \mathrm{L}$, corresponds to yield of 0.142 $\mathrm{g} / \mathrm{g}$ of native cotton stalk, $0.221 \mathrm{~g} / \mathrm{g}$ of holocelluloses and $0.355 \mathrm{~g} / \mathrm{g}$ of fermentable sugars in first batch; and $3.96 \mathrm{~g} / \mathrm{L}$ corresponds to a yield of $0.143 \mathrm{~g} / \mathrm{g}$ of native cotton stalk, $0.222 \mathrm{~g} / \mathrm{g}$ of holocelluloses and $0.356 \mathrm{~g} / \mathrm{g}$ of fermentable sugars in subsequent batch fermentation respectively. The fermentation efficiencies in first and second cycle were noted as $69.53 \%$ and $69.88 \%$ respectively.

Table.1 Ethanol fermentation from cotton stalk hydrolysate by using immobilized culture of Saccharomyces cerevisiae and Pachysolen tannophilus

\begin{tabular}{lcccccc}
\hline \begin{tabular}{l} 
Time $\begin{array}{l}\text { Timiod } \\
\text { peri } \\
(\mathbf{h r})\end{array}$ \\
\hline 6
\end{tabular} & $\begin{array}{c}\text { Ethanol conc. } \\
(\mathbf{g} / \mathbf{L})\end{array}$ & \multicolumn{3}{c}{ Ethanol yield (g/g) } & $\begin{array}{c}\text { Fermentation } \\
\text { efficiency }(\%)\end{array}$ & $\begin{array}{c}\text { Sugar } \\
\text { consumed } \\
(\%)\end{array}$ \\
\cline { 2 - 6 } & 00 & 000 & 000 & 000 & 00 & 12.70 \\
12 & 0.71 & 0.026 & 0.040 & 0.064 & 12.53 & 26.29 \\
24 & 2.08 & 0.075 & 0.116 & 0.187 & 36.71 & 52.38 \\
36 & 3.94 & 0.142 & 0.221 & 0.355 & 69.53 & 90.18 \\
48 & 3.92 & 0.141 & 0.220 & 0.353 & 69.18 & 90.21 \\
60 & 3.91 & 0.141 & 0.219 & 0.352 & 69.00 & 90.27 \\
72 & 3.89 & 0.140 & 0.218 & 0.350 & 68.65 & 90.29 \\
\hline SEm \pm & 0.16 & 0.007 & 0.007 & 0.0019 & 00.38 & 1.72 \\
CD at & 0.47 & 0.021 & 0.021 & 0.0060 & 01.17 & 5.20 \\
$5 \%$ & & & & & & \\
\hline
\end{tabular}


Table.2 Effect of recycling on immobilized culture of Saccharomyces cerevisiae and Pachysolen tannophilus

\begin{tabular}{|c|c|c|c|c|c|c|}
\hline \multirow{2}{*}{$\begin{array}{l}\text { Ferment- } \\
\text { ation cycles }\end{array}$} & \multirow{2}{*}{$\begin{array}{c}\text { Ethanol } \\
\text { conc. } \\
\text { (g/L) }\end{array}$} & \multicolumn{3}{|c|}{ Ethanol yield (g/g) } & \multirow{2}{*}{$\begin{array}{c}\text { Fermentation } \\
\text { efficiency } \\
(\%)\end{array}$} & \multirow{2}{*}{$\begin{array}{c}\text { Sugar } \\
\text { consumed } \\
(\%)\end{array}$} \\
\hline & & Biomass & Holocelluloses & $\begin{array}{c}\text { Fermentable } \\
\text { sugar }\end{array}$ & & \\
\hline First batch & 3.94 & 0.142 & 0.221 & 0.355 & 69.53 & 90.18 \\
\hline $\begin{array}{l}\text { Second } \\
\text { batch }\end{array}$ & 3.96 & 0.143 & 0.222 & 0.356 & 69.88 & 97.26 \\
\hline Third batch & & \multicolumn{5}{|c|}{ Destruction of Ca-alginate beads occurred } \\
\hline
\end{tabular}

Fig.1 Effect of time on ethanol concentration from cotton stalk hydrolysate by immobilized coculture of Saccharomyces cerevisiae and Pachysolen tannophilus

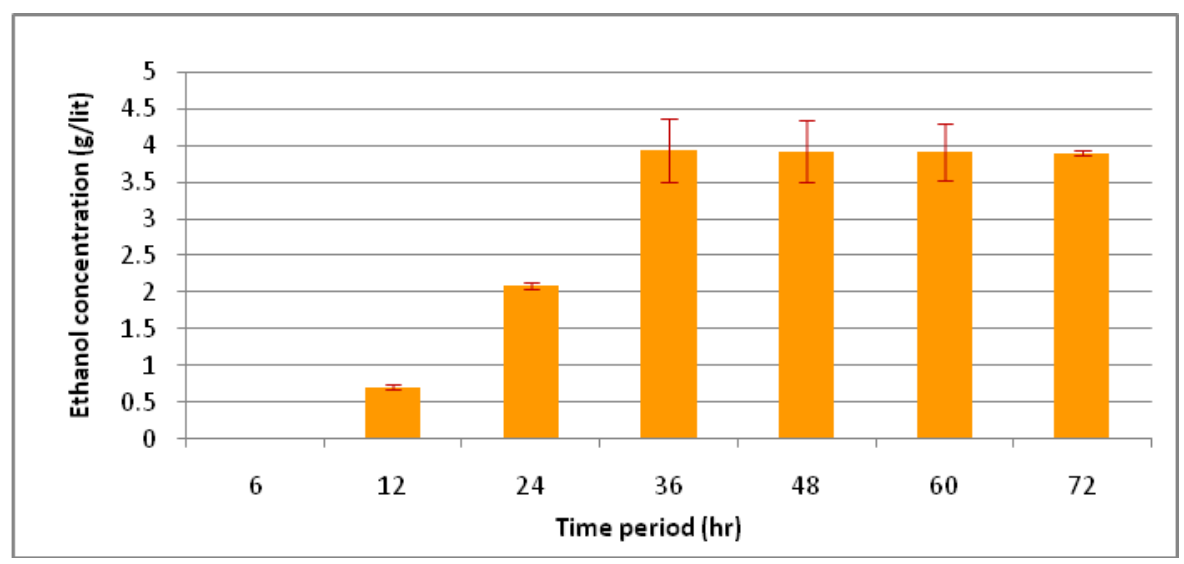

Fig.2 Effect of time on ethanol yield from cotton stalk hydrolysate by immobilized co-culture

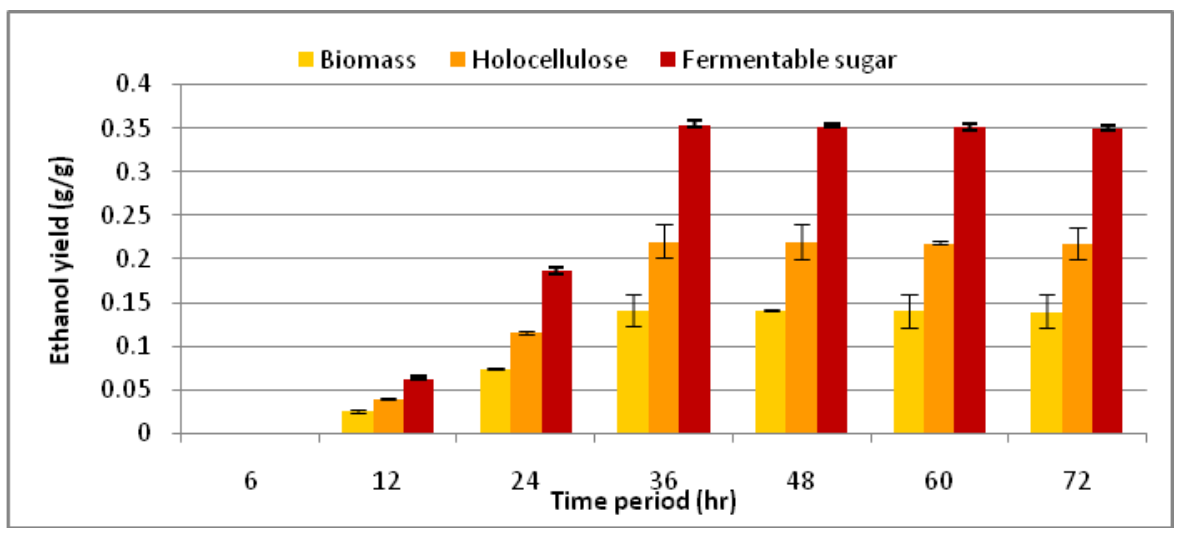


Fig.3 Fermentation efficiency and sugar consumed during ethanol fermentation

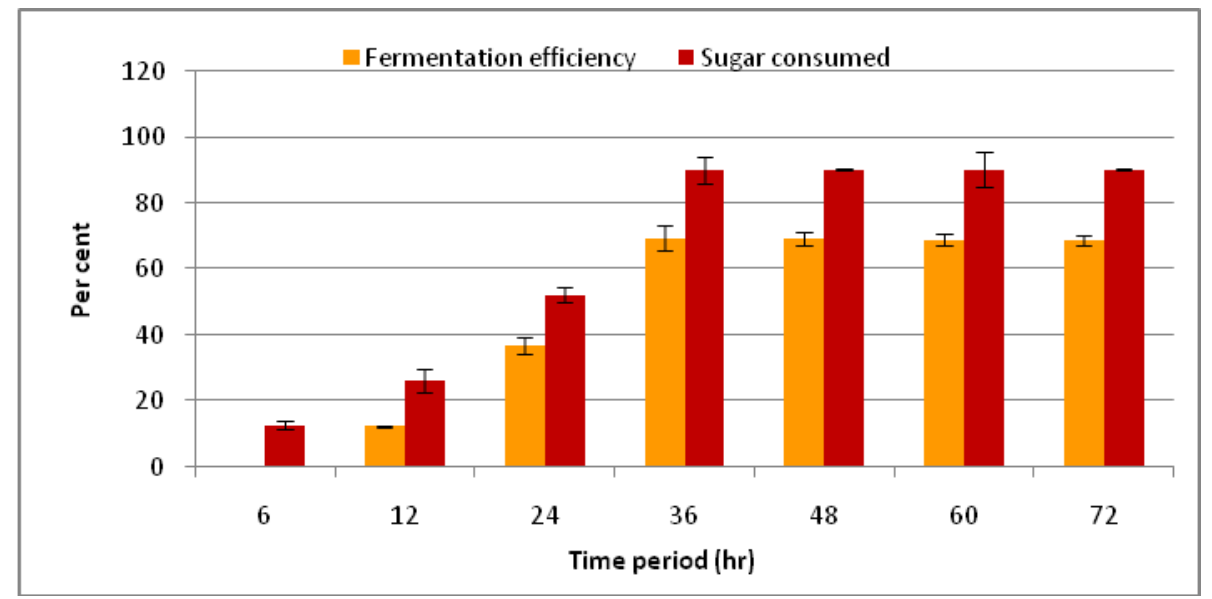

The ethanol concentration and ethanol yield remain almost constant during the repeated batch fermentation, as was observed from obtained results shown in Table 2. It was interesting to note that immobilized yeast cell effectively consumed more than $90 \%$ sugar in both cycles, while beads dimension was observed slightly increased in subsequent cycles. However, during third cycle of fermentation resulted in destruction of Ca-alginate beads occurred, and this was might be due to intensive growth of cells and $\mathrm{CO}_{2}$ evolution during the fermentation. The intensive proliferation of yeast cells inside the matrix caused instability of $\mathrm{Ca}$ alginate in acid condition during fermentation, as was reported by Rakin et al., (2009). It was considered that, after repeated cycles the overgrowth of test organisms in the gel beads caused inhibition of substrate diffusion (sugars) inside and the product (ethanol) outside (Aithal, 2001). Bakers et al., (2001) investigated batch fermentation of sucrose using Zymomonas mobilis cells immobilized in Ca-alginate and reported that $\mathrm{Ca}$-alginate beads disintegrated after 4-5 days. From one more investigation, it has also been reported that, maximum ethanol production was observed up to $4^{\text {th }}$ cycle in repeated batch fermentation system from glucose as carbon source using
Saccharomyces cerevisiae $\mathrm{VS}_{3}$ immobilized in calcium alginate beads (Sree et al., 1999). While in present study comparatively less repeated cycles were possible, which might be due to presence of traces of inhibitors even after detoxification. It was observed that, though immobilized cell fermentation is preferred with respect to the advantages of high cell concentration and easy separation of biocatalysts, maintenance of the mechanical structure of the gel matrix usually requires additional attention. Therefore, compared to batch culture, continuous cultivation of the hydrolysate with regular input of the fresh immobilized cells during fermentation is supposed to be better option for ethanol production, as was also recommended by Yang (2008).

In addition to the present study, various carriers may also use in future to make the process more feasible and productive. In this regards, Rakin et al., (2009), investigated the effect of immobilized Saccharomyces cerevisiae using $\mathrm{Ca}$-alginate using corn meal hydrolysate for bioethanol production for repeated batch fermentation and found that alginate gels degraded after the second fermentation cycle, while PVA carrier exhibited better mechanical properties and stability, however lower ethanol 
concentration were achieved during the fermentation.

In conclusion, a successful attempt has been made to immobilize the cell of Saccharomyces cerevisiae and Pachysolen tannophilus in calcium alginate matrix and from this; peak ethanol concentration of $3.94 \mathrm{~g} / \mathrm{L}$ (corresponds to yield of $0.355 \mathrm{~g} / \mathrm{g}$ of available sugar) was achieved after $36 \mathrm{~h}$ of fermentation. Recycling of immobilized cell showed no significant change in concentration, yield and fermentation efficiency were observed in between first two batches, and during third cycle, beads became disintegrated. The present study is limited to laboratory scale only, and sincere efforts are needed to make the process more feasible and economical.

\section{References}

Aithal, S.C. 2001. Studies on utilization of blackened sorghum for production of ethanol. Ph.D. Thesis. Swami RamanandTeerth Marathwada University, Nanded.

Baig, M.Z. 2014. Studies on production of bioethanol from cotton stalk (Ph.D. thesis), Dr. BabasahebAmbedkar Marathwada University, Aurangabad, India.

Baig, M.Z., and Dharmadhikari, S.M. 2014.Optimization of detoxification with over liming and charcoal treatment for increasing the fermentability of cotton stalk hydrolysate. Ind. J. of Appl. Res., 4(07): 08-10.

Bakers, M., Laukevics, J., Karsakevich, A., Ventina, E., Kaminska, E., Upite, D., Vina, I., Linde, R., and Scherbaka, R. 2001. Levan-ethanol biosynthesis using Zymomonasmobilis cells immobilized by attachment and entrapment. Process Biochem., 36: 979-986.

Baptista, C.M.S.G., Colas, J.M.A., Oliveira, A.C.M., Oliveira, N.M.C., Roche, J.M.C., Dempsey, M.J., Lannigan, K.C., and Benson, P.S. 2006. Natural immobilization of microorganism for continuous ethanol production. Enzyme. Microb. Technol., 40: 127131.

Bregmeyer, H.U., Gawehn, K., and Grassl, M. 1974. Methods of enzymatic analysis (Bregmeyer, H.U., ed) Academic Press. Inc., 1(2): 457-458.

Carvalho, W., Silva, S.S., Converti, A., Viltolo, M., Felipe, M.G.A., Roberto, I.C., Silva, M.B., and Manciha, I.M.2002. Use of immobilized Candida yeast cells for xylitol production from sugarcane bagasse hydrolysate. Appl. Biochem. Biotechnol., 98-100:489-496.

Chandel, A.K., Kapoor, R.K., Singh, A., and Kuhad, R.C. 2007. Detoxification of sugarcane bagasse hydrolyzate improves ethanol production by Candida shehatae NCIM 3501. Bioresour. Technol., 98: 1947-1950.

Davis, T.A., Volesky, B., and Mucci, A.2003. A review of the biochemistry heavy metal bio sorption by brown algae. Water. Res., 37:4311-30.

Dien, B.S., Iten, L.B., and Bothast, R.J. 1999. Conversion of corn fiber to ethanol by recombinant E.coli strain FBR3. J. Ind. Microbiol., 22: 575-581.

Goksungur, Y., and Zorlu, N. 2001. Production of ethanol from beet molasses by $\mathrm{Ca}$-Alginate immobilized yeast cells in a packed bed bioreactor. Turk. J. Boil., 25: 265-275.

Kourkoutas, Y., Bekatorou, A., Banatb, I.M., Marchant, R., and Koutinas, A.A. 2004. Immobilization technologies and support materials suitable in alcohol beverages 
production: a review. Food. Microbiol., 21(4): 377-397.

Liao, W., Liu, Y., Liu, C., Wen, Z., and Chen, S. 2006. Acid hydrolysis of fiber from dairy manure. Bioresour. Technol., 97: 1687-1695.

Martinez, A., Rodriguez, M.E., York, .S.W., Preston, J.F., and Ingram, L.O.2000. Effect of $\mathrm{Ca}(\mathrm{OH})_{2}$ treatments ("overliming") on the composition and toxicity and bagasse of hemicellulose hydrolyzates. Biotechnol. Bioeng., 69: 526-536.

Miller, G.L.1959. Use of dinitrosalicylic acid reagent for determination of reducing sugars. Anal. chem., 31: 426428.

Rakin, M., Mojovic, L., Nikolic, S., Vukasinovic, M., and Nedovic, V.2009. Bioethanol production by immobilized Saccharomyces cerevisiae var. ellipsoideus cells. Afr. J. Biotechnol., 8(3): 4645-471.

Singleton, V.L., Rossi, J.A. 1965. Colorimetric of total phenolics with phosphomolybdic-phosphotungstic acid reagents. Am. J. Enol. Viticult., 16: 144-158.

Sree, K.N., Sridhar, M., Suresh, K., and Rao, L.V.1999. High alcohol production by solid substrate fermentation from starchy substrates using thermo tolerant Saccharomyces cerevisiae. Bioproc. Eng., 20: 561563.

Srilekha Yadav, K., Naseeruddin, S., Prashanthi, G.S., Sateesh, L., and Rao, L.V. 2011. Bioethanol fermentation of concentrated rice straw hydrolysate using co-culture of Saccharomyces cerevisiae and Pichia stipites. Bioresour. Technol., 102(11): 64736478.

Teramoto, Y., Lee, S-H, and Endo, T.2008. Pre treatment of woody and herbaceous biomass for enzymatic saccharification using sulfuric acidfree ethanol cooking. Bioresour. Technol., 99: 8856-8863.

Vullo, D.L., and Wachsman, M.B.2005. A simple laboratory exercise for ethanol production by immobilized bakery yeasts (Saccharomyces cerevisiae) (Lab Exercises/Demonstrations). $J$. Food. Sci. Edu., 4: 53-55.

Wendhausen, R., Fregonesi, A., Moran, P.J.S., Joekes, I., Rodrigues, J.A., Tonella, E., and Althoff, K. 2001. Continuous fermentation of sugar cane syrup using immobilized yeast cells. $J$. Biosci. Bioeng., 9(1): 48-52.

Yang, Y. 2008. Ethanol production potential of acid pre treated switch grass varieties. Master's Thesis. North Carolina State University.

\section{How to cite this article:}

Mirza Zaheer Baig and Smita M. Dharmadhikari. 2016. Bioethanol Production from Cotton Stalk Hydrolysate using Immobilized Co culture of Saccharomyces cerevisiae and Pachysolen tannophilus. Int.J.Curr.Microbiol.App.Sci. 5(12): 389-397.

doi: http://dx.doi.org/10.20546/ijcmas.2016.512.043 